\title{
ALIMENTOS À MESA: DIDÁTICA PARA ASSIMILACCÃO DE CONTEÚDOS NO CENTRO DE ENSINO MÉDIO BENJAMIM JOSÉ DE ALMEIDA, NA CIDADE DE ARAGUAÍNA - TO
}

Food At The Table: Didactics For Assimilation Of Contents In The Centro De Ensino Médio

Benjamim José De Almeida, In The City Of Araguaína - TO

Alimentos En La Mesa: Didáctica Para La Asimilación De Contenidos En El Centro De

Ensino Médio Benjamim José De Almeida, En La Ciudad De Araguaína - TO

Solandia Teixeira Oliveira ${ }^{1}$, Bruno Caio Moreira Silveira ${ }^{1}$, Milena Alves dos Santos Vulcão ${ }^{2}$, Antônia Márcia Duarte Queiroz ${ }^{3}$

${ }^{1}$ Curso de Biologia na Universidade Federal do Tocantins Araguaína, Brasil.

${ }^{2}$ Professora de Biologia, Diretoria Regional de Educação de Araguaína, Brasil

${ }^{3}$ Professora Adjunta, Curso de Geografia, universidade Federal do Tocantins, Araguaína, Brasil

\section{Artigo recebido em 10/04/2020 aprovado em 15/04/2020 publicado em 18/04/2020}

\section{INTRODUÇÃO}

Tendo em vista que a alimentação deve ser nutricionalmente equilibrada, contendo alimentos saudáveis e procurando evitar ao máximo o uso de alimentos industrializados em sua composição, com o intuito de obter um percentual agradável na prevenção de problemas de saúde decorrentes de uma alimentação inadequada, e analisando ainda a maneira como estes são oferecidos às crianças tanto no âmbito escolar como em seus lares, é que pensamos este projeto. Pois a partir do mesmo, os alunos poderão obter-se de um pensamento crítico mais concreto acerca da alimentação consumida, podendo ainda, perpassá-lo, influenciando essa melhoria para as pessoas do seu círculo social.

$\mathrm{O}$ presente projeto visa auxiliar o desenvolvimento alimentar das crianças do $1^{\mathrm{a}}$ ano do ensino médio do Centro de Ensino Médio Benjamim José de Almeida, na cidade de Araguaína-TO, com intuito de propiciar condições de concretização dos conceitos relativos ao tema, uma vez que se tratam de conhecimentos prévios, disponibilizando um atendimento as preferências alimentares das crianças, bem como os aspectos nutricionais.

É imprescindível estimular práticas alimentares saudáveis nas crianças, por meio de conceitos e exposições metodológicas em sala, buscando influenciar em seus hábitos alimentares, lembrando que uma alimentação correta, ou seja, aquela que supre de maneira eficiente toda a necessidade diária, serve como base para a saúde física e mental, podendo auxiliar de forma direta no bom rendimento intelectual dos discentes.

\section{METODOLOGIAS E MATERIAIS}

O Projeto foi desenvolvido por meio da metodologia ativa, onde os estudantes das turmas de $1^{\text {a }}$ ano com aproximadamente 39 alunos cada, se envolveram efetivamente em todas as etapas do projeto. A ação segue o modelo de sala de aula invertida, o qual consiste na inversão do 
papel do professor tornando um mediador no processo de ensino. Os estudantes são protagonistas do processo de busca do conhecimento. Com o conteúdo prévio que foi repassado pelo professor, o estudante se utiliza da autonomia de pesquisa e da tentativa de resolver exercícios e identificar suas dúvidas.

A metodologia ativa parte do princípio de que os estudantes tenham o primeiro contato com o conteúdo antes de chegarem na escola e só após esse contato poderão ser auxiliados pelo professor, ou seja a partir das dúvidas que surgiram mediante a resolução dos exercícios. A princípio com a coleta de dados referentes aos alimentos encontrados no cardápio escolar e sobre os hábitos alimentares de todos os envolvidos no projeto.

Posteriormente, com uma sequência de aulas teóricas com apresentações de vídeos educativos demonstrando o quanto é importante e prazeroso ter uma alimentação que contemple cereais, vegetais, frutas, carne e leite em suas quantidades/porções corretas, como forma de incentivo ao consumo de uma alimentação saudável. Em outra etapa foram desenvolvidas práticas experimentais para o conhecimento dos nutrientes contidos nestes alimentos.

Realizamos conjuntamente um momento, o qual denominamos de "saúde a mesa", onde nos dividimos em pequenos grupos, cada um destes segmentados conforme os nutrientes: carboidratos, lipídios, proteínas e vitaminas. Ficando assim, responsáveis por trazer alimentos conforme o nutriente especificado para o grupo, afim de que fossem expostos na sala de aula.
E, a criação de uma composteira foi realizada por todos nós, juntamente com os professores e estudantes das turmas supracitadas.

\section{RESULTADOS E DISCUSSÃO}

$$
\text { Segundo Azenha (2006), o }
$$

construtivismo de Jean Piaget é uma teoria constituída pela força da ação de interação do indivíduo com o meio físico e social, partindo da ideia de que o conhecimento não é dado como algo terminado, mas sim como resultado da força das relações sociais.

Utilizando da metodologia ativa, o docente pode organizar o processo, de modo a permitir e incentivar a cooperação dos discentes no ambiente pedagógico, entre os mais e menos avançados, entre os que têm maior afinidade com certas disciplinas e os que têm para outros conhecimentos.

De acordo com Koivisto\&Rozin apud Ramos \& Stein (2008) o comportamento alimentar quando se refere aos alunos é definido em primeiro momento pela família, da qual pertence e depende, em segundo momento pelas outras interações psicossociais e culturais da criança. E é nesse período que devem ser introduzidos os bons hábitos alimentares, que permanecerão durante a adolescência e na vida adulta (DUTRA-DE-OLIVEIRA, 1998).

Além dos aspectos que proporcionam prazer, a alimentação saudável favorece ao nosso organismo energia e outros nutrientes que o corpo precisa para crescer, desenvolver e manter a saúde, sendo a variação desses alimentos indispensáveis para que seja possível que nosso organismo receba todos os tipos de nutrientes. 
(EUCLYDES, 2000). A má alimentação, em contrapartida, pode ser considerada um dos fatores motivadores para o surgimento de doenças crônico-degenerativas no ser humano, principal causa de mortalidade no adulto. (RAMOS \& STEIN, 2000).

O tema de promoção de saúde na escola torna-se um eixo importante em nível nacional, deixando clara a visão de que a escola é um espaço de ensino aprendizagem, convivência e crescimento importante, no qual se adquirem valores fundamentais. A escola é o lugar ideal para se desenvolverem programas da Promoção e Educação em Saúde de amplo alcance e repercussão, já que exerce grande influência sobre seus alunos nas etapas formativas e mais importantes de suas vidas. (GONÇALVES, 2008).

Foi cognoscível o manifesto da eficácia em aulas, quando trazemos aos alunos um diferencial nessa prática com aulas didáticas metodológicas. Aos alunos do Centro de Ensino Médio Benjamim José de Almeida, em especifico às turmas que tiveram acesso a esta aula, um rendimento positivo quando se trata do alcance de notas foi algo concreto, visto isso no quadro geral dos resultados das provas $\mathrm{e}$ atividades sobre tais temáticas.

\section{CONCLUSÃO}

Houve melhora no rendimento escolar na disciplina de biologia, no Colégio Benjamim. Portando, compreende-se assim, a importância das práticas desenvolvidas, por meio da aplicação do projeto de intervenção. Assim, vai se tornando mais concreto, situações e experiências que traziam dúvidas hoje sanam-se, em sua maioria resultantes da nossa prática. Já é possível visualizar resultados positivos, trazernos base para um aprimoramento no que ainda há por vir.

\section{AGRADECIMENTO}

Agradecemos as instituições de ensino Universidade Federal do Tocantins, o Colégio CEM Benjamim José de Almeida e Capes, pelas oportunidades e parceria durante todo o projeto.

Todos os autores declararam não haver qualquer potencial conflito de interesses referente a este artigo.

\section{REFERÊNCIAS}

AZENHA, M. G. Construtivismo: de Piaget a Emília Ferreiro. $8^{\circ}$ ed. São Paulo: Ática, 2006.

DUTRA de OLIVEIRA, J.E.; Macro minerais, Ciências Nutricionais. São Paulo: Sarvier. 1998. EUCLYDES, M.P. Alimentação Complementar.
GONÇALVES, F. D.; CATRIB, A. M. F.; VIEIRA, N. F. C.; VIEIRA, L. J. E. S.; A Promoção da saúde na educação infantil. Com Saúde Educ, v.12, n.24, p. 181-92, jan/mar. 2008.

RAMOS, Mauren; STEIN, Lilian. Desenvolvimento do comportamento alimentar infantil. Jornal de Pediatria; 2000.

VALLE, J. M. N.; EUCLYDES, M. P.; A formação dos Hábitos Alimentares na Infância: uma revisão de alguns aspectos abordados na literatura nos últimos dez anos, Juiz de Fora - MG, 2003. 